\title{
Impact of Monetary Policy Shocks on Macroeconomic Fundamentals: The Role of Asymmetry and Uncertainty in Nigeria
}

\author{
LeeLee N. Deekor \\ Department of Economics, \\ Ignatius Ajuru University of Education, \\ Port Harcourt, Nigeria.
}

\begin{abstract}
That monetary policy is made in an environment of substantial uncertainty is only a commonplace knowledge. But for the peculiar vulnerability of monetary authorities to exogenous conditions in developing economies, we hypothesized for the role of uncertainty in the asymmetry effect of monetary policy. Essentially, we explore both money supply and interest rate process using linear and non-linear ARDL to show that political pressure such as variability in government borrowing has the potential to accelerate the asymmetry effect of monetary policy. We also observe the asymmetry effect of monetary policy to be sensitive to the choice of monetary policy indicator. These findings suggest that monetary authorities must consider not only the effectiveness or otherwise of monetary policy instruments to affect the target policy goals, but also the fact that not all the target variables react in a similar way to expansionary and contractionary monetary policy shocks.
\end{abstract}

Keywords: Monetary Policy Shocks; Asymmetry Effects; Uncertainty; Developing Economies

\section{INTRODUCTION}

Nonetheless the proliferation of papers on the relationship between monetary policy and the target variables namely, output and inflation; the literature has continued to throw up debate with respect to the effectiveness of monetary policy to affect these policy variables. To put it differently, despite the widely accepted long term neutrality of monetary policy, there has been lack of consensus regarding the short term effect of monetary policy. This may not be unconnected to the uncertainty associate with direction of policy change, size of policy shocks and/or state of the economy. For instance, the Taylor rule has remained the basis upon which the response of monetary authorities is assumed to be symmetric. However, there has been increasing evidence challenging the view that central banks use simple linear interest rules (see for example, Gerlach, 2000; Gerlach and Schnabel, Cukierman andMuscatelli, 2008).

Given their aversion for under-employment, the central bank has the potential to react more aggressively to negative output gaps, but act passively when the situation is that of overemployment. Another potential source of asymmetries in monetary policy stem from the existence of non-linear Phillips curve (see for example, Castro, 2011). These studies are though differ in terms of data and methodology, yet their findings uniformly suggest that changes in the target interest rate result in a weaker effect of monetary policy when inflation is high. This according to the author(s) is an indication that the interest rate behaviour of monetary authorities is more aggressive during the periods of high inflation compared to the period of low inflation. There is also the tendency of the existence of political pressure acting as a deterrent to central banks such that they favour a pre-emptive contractionary monetary policy even when the economic situation might be suggesting otherwise. 
Decipherable from the above is probable asymmetry function of monetary policies. Thus, there have been growing efforts in the literature to understand the asymmetry effects of monetary policy on the target variables (see Weise, 1999; De Grauwe, 2000; Gros and Hefeker, 2002; Nolan, 2002; Aksoy et al., 2002; De Grauwe and Se'ne'gas, 2006; Ouyang and Wang, 2009; Ravn, 2013; Karras, 2013; Zakir and Malik, 2013; Santoro et al., 2014; Georgiadis, 2015; Lee and Yoon, 2016; Scot, 2016; Kilinc and Tunc, 2017; Zhu and Chen, 2017; Fang et al., 2018; Gogas et al., 2018). Despite the vastness of literature on the asymmetry effects of monetary policy, the empirical findings have been hugely mixed with little or no consensus on the extent to which asymmetries matter for the effectiveness of monetary policy. Such mixed results might be due to the problem of model misspecifications, foremost by the omission of some potential as the underlying source of asymmetries in monetary policy.

In line with some of our earlier submission particularly in the second paragraph of this section, both academics and policymakers agree that monetary policy is made in an environment of substantial uncertainty regarding the current and future economic conditions as well as the functioning of the economy (see Monte, 2010). This notwithstanding, quite a number of the extant studies have continued to ignore the potential of uncertainty as capable of generating asymmetries in monetary policy. To put it differently, most of the previous studies on asymmetry effects of monetary policy drawn their inference from model(s) that do not account for uncertainty. The closer to the present paper is the study by De Grauwe and Se'ne'gas (2006). Motivated by the probable presence of heterogeneity in the national transmission channels of monetary policy, De Grauwe and Se'ne'gas (2006) uses the case of European Monetary Union (EMU) to show that uncertainty matters in the asymmetry effects of monetary policy. However, it must be pointed out that these authors mainly focused on the case of developed economies, where monetary authorities are highly independent of political pressure.

There is also the likelihood of nominal shocks having different effects in developing countries compared with the developed ones (Zakri and Malik, 2013). For instance, output in the developed countries is to be determined on the demand side, but the developing economies on the other hand are rather characterized with all sorts of supply constraints (i.e. food supply). Hence, while a contractionary monetary policy might constitute stagflation in these countries, it might be a higher inflation for an expansionary monetary policy. Thus, while acknowledging the contribution of De Grauwe and Se'ne'gas (2006) on the role of uncertainty in the asymmetry effects of monetary policy, it might be erroneous to generalizing their findings for both the developed and developing economies. Our contribution to literature is therefore, in three fold:

First, unlike the previous studies, we focus on an environment, where monetary authorities are highly vulnerable to political pressure and other exogenous conditions. To this end, we describe uncertainty from the view point of the vulnerability of decision -making process such as central bank's decision to political pressure and other exogenous conditions. Then we hypothesized the potential of uncertainty as the underlying source of asymmetries and that it matters for the asymmetry effects of monetary policy. Secondly, we explore both the internal and external indicators of exogenous conditions to determine whether the choice or measure of uncertainty does matter for the asymmetry effects of monetary policy. Third, we ascertain the robustness of our findings using alternative measure of monetary policy shocks.

Besides this introductory section, the paper presents five more sections: The next section presents the theoretical foundations of asymmetries in monetary policy. Section three discusses the data and the choice of Nigeria as a case study. Section four explains the model 
and estimation procedure. Section five presents and discusses the empirical findings. The sixth section concludes the paper and offers some recommendations.

\section{THEORETICAL FOUNDATIONS OF ASYMMETRIES IN MONETARY POLICY}

There are several theoretical reasons why monetary policy could have asymmetric effects on aggregates such as output, prices and exchange rates (see Zakir and Malik, 2013). However, it is the Keynesian interpretation that prices and wages are sticky downward and flexible upward that has remained the workhorse for analyzing the asymmetry effect of monetary policy. This approach attribute the potential of asymmetries in monetary to the fact that prices are likely to be "sticky" or less likely to adjust downward. Consequently, it is suggested that an expansionary monetary policy is likely to be less effective than the contractionary monetary policy. That is, for the downward and rigidity nature of prices and wages, firms are most likely to respond to contractionary monetary policy by reducing output rather than prices. Hence, contractionary and expansionary monetary policies are likely to give different consequences when prices or wages are rigid in the direction of downward but flexible in the direction of upward. This by implication generates a "kinked" aggregate supply curve such that negative (contractionary) monetary shocks are asymmetric (see Tan et al., 2010).

Similar to the Keynesian interpretation are models with cost of menu strategy. The cost of menu approach relate the source of asymmetry in monetary policy to the fact that firms keep prices constant in response to a small shift in nominal demand so as to avoid menu cost (see Wooheon, 1995; Zakir and Malik, 2013). It is on this note that big monetary shocks has been widely proclaimed as likely to be neutral, but same cannot be said of small monetary shocks thereby constituting asymmetries in monetary policy. There are also the "credit view" approach suggesting that firms are likely to encounter credit constrain during recessionary period than they would in expansions. According to credit -rationing hypothesis as explained by Bernanke and Gertler (1989), a tight monetary policy will increase the cost of capital as well as lessen the liquidity and in turn prompt a contraction of investment demand for investors who are already facing credit constraints.

\section{Data source and variable description}

\section{DATA AND PRELIMINARY ANALYSIS}

Variables used in the context of this study are selected based on their theoretical importance as well as their uses and findings in the previous empirical literature. For monetary policy indicators, we find money supply and interest rate as the most prominent in the empirical literature. notable indicators of monetary policy in the literature. Other most widely used variables in the monetary economics are output, inflation and exchange rates, while researchers also used to control for government influence via some fiscal side such as government borrowing. In addition to controlling for such government influence which is almost conventional in the literature, one of the main innovations of this study is to determine the extent to which the uncertainty feature of such exogenous condition matters for the asymmetry effect of monetary policy. For monetary policy measure, virtually all the empirical literature on the asymmetry effects of monetary policy used unanticipated monetary policy shocks for instance the residual of the estimated money supply equation (see for example, Karras, 2013; Zakir and Malik, 2013; Gogas, et al., 2018).

For the output variable $(Y)$, industrial production index $(I P I)$ has been used in the literature. The interest rate (INRT) is measured using prime lending rate while inflation (INFL) is measured using consumer price index. The exchange rate $(E R)$ variable is captured via Naira/USD. The indicators for uncertainty are calculated for both internal and external exogenous conditions. We use the variability of government borrowing (GVB) as a proxy for 
the former (internal uncertainty $\left(U C^{i}\right)$ ), while the variability of international oil prices (OP) is consider most appropriate in the case of external uncertainty $\left(U C^{e}\right)$ given the oil dependent feature of the investigated economy. The underlying framework for the computation of the uncertainty is the Generalized Conditional Heteroscedasticity (GARCH). For detail on the various advantages of using the GARCH framework for modelling or computing uncertainty (see, Berger and Herz (2013) provide).

The choice of Nigeria as the investigated economy is mainly informed by the relatively higher degree of the country's monetary policy to political pressure and other exogenous conditions. All the data are in quarterly period sourced from CBN statistical bulletin as well as the International Financial Statistics (IFS) database. The start date for the sourced data is first quarter of 1981 and the end date is fourth of quarter 2017 totaling 148 observations. Although, quite a reasonable number of the variables of interest are available on monthly frequency, however; the highest accessible frequency for IPI a proxy for output variable is quarterly period in the case of Nigeria.

\section{Preliminary analysis}

Starting with the summary statistics where all the variables are expressed in their respective original unit of measurement, the average money supply and interest rate for the period under consideration is $\mathrm{N} 2291.47$ billion and $17.92 \%$, respectively. However, the standard deviation statistics for the individual variables cannot be compared in absolute term and that is because the variables are expressed in varying unit of measurement. For the purpose of comparative therefore, we normalize the standard deviation statistics and a cursory look at Table 1 shows that money supply, inflation measure via consumer price index and government borrowing a proxy for internal uncertainty are the most volatile given the relative higher value of their respective standard deviation statistics. With respect to the statistical distribution of the variables, all the series appear to be positively skewed but output. Similarly, the kurtosis statistics is mostly platykurtic except for money and supply and output variables that seems otherwise (leptokurtic). On the whole, the computed probability values associated with the Jarque-Bera normality test statistic appears to be less than 0.05 implying the rejection of the hypothesis that the series are normally distributed at $5 \%$ level of significance.

Table 1: Summary Statistics

\begin{tabular}{|c|c|c|c|c|c|c|c|}
\hline & Mean & STDV & N-STDV & Skewness & Kurtosis & JB stat. & Obs \\
\hline$M_{t}$ & 2291.47 & 3099.32 & 1.35 & 1.12 & 2.70 & $31.57(0.00)$ & 148 \\
\hline$I N T R_{t}$ & 17.92 & 5.19 & 0.29 & 0.34 & 4.80 & $22.95(0.00)$ & 148 \\
\hline$Y_{t}$ & 89.15 & 21.60 & 0.24 & -0.43 & 2.31 & $7.40(0.02)$ & 148 \\
\hline$I N F L_{t}$ & 55.60 & 63.37 & 1.14 & 1.18 & 3.45 & $35.72(0.00)$ & 148 \\
\hline$E R_{t}$ & 82.79 & 80.04 & 0.97 & 0.77 & 3.11 & $14.81(0.00)$ & 148 \\
\hline$M P R_{t}$ & 13.23 & 3.75 & 0.28 & 0.75 & 4.24 & $23.14(0.00)$ & 148 \\
\hline$G V B$ & 3531.98 & 3957.32 & 1.12 & 1.32 & 4.07 & $50.33(0.00)$ & 148 \\
\hline$O P$ & 42.09 & 31.05 & 0.74 & 1.23 & 3.29 & $37.91(0.00)$ & 148 \\
\hline
\end{tabular}

Note: STDV represents standard deviation while N-STDV is the normalize standard deviation computed as: STDV/mean, while the values in parenthesis are the probability values associated with the Jaque-Berra (JB) statistic.

As a precondition for dealing with time series, we further subject each of the series to unit root tests. For robustness purpose, we consider both the Augmented Dickey-Fuller (ADF) test and the modified version namely, Dickey-Fuller GLS (DF-GLS) test. Presented in Table 2 is the unit root test result which is performed on the natural logarithm of the series. Strengthening our 
choice of estimation technique for instance ARDL framework is the mixed integration properties exhibited by the variables. For instance, a look at table 2 below shows that the integration properties for each of the series hover between I(0) and I(1) nonetheless the choice of unit root test.

Table 2: Unit Root Test Results

\begin{tabular}{|c|c|c|c|c|c|c|}
\hline & \multicolumn{5}{|c|}{ ADF test } & \multicolumn{3}{c|}{ DF-GLS test } \\
\cline { 2 - 7 } & Level & First Difference & $\mathrm{I}(\mathrm{d})$ & Level & First Difference & $\mathrm{I}(\mathrm{d})$ \\
\hline$M_{t}$ & $-1.1778^{\mathrm{a}}$ & $-3.5973^{\mathrm{b} * *}$ & $\mathrm{I}(1)$ & $-1.5318^{\mathrm{b}}$ & $-2.3824^{\mathrm{a} * *}$ & $\mathrm{I}(1)$ \\
\hline$I N T R_{t}$ & $-2.7825^{\mathrm{a}^{*}}$ & - & $\mathrm{I}(0)$ & $-1.4034^{\mathrm{b}}$ & $-11.0530^{\mathrm{b} * * *}$ & $\mathrm{I}(1)$ \\
\hline$Y_{t}$ & $-3.0929^{\mathrm{b}}$ & $-3.0929^{\mathrm{a} * * *}$ & $\mathrm{I}(1)$ & $-2.8357^{\mathrm{b} *}$ & - & $\mathrm{I}(0)$ \\
\hline$I N F L_{t}$ & $-1.8799^{\mathrm{b}}$ & $-3.5992^{\mathrm{a} * * *}$ & $\mathrm{I}(1)$ & -1.2043 & $-3.8062^{\mathrm{b} * * *}$ & $\mathrm{I}(1)$ \\
\hline$E R_{t}$ & $-1.9305^{\mathrm{a}}$ & $-10.5683^{\mathrm{b} * * *}$ & $\mathrm{I}(1)$ & $-0.9436^{\mathrm{b}}$ & $-10.6324^{\mathrm{b} * * *}$ & $\mathrm{I}(1)$ \\
\hline$M P R_{t}$ & $-2.6028^{\mathrm{a}}$ & - & $\mathrm{I}(0)$ & $-2.1035^{\mathrm{a} * *}$ & - & $\mathrm{I}(0)$ \\
\hline$U C_{t}^{i}$ & $-6.9461^{\mathrm{b} * * *}$ & - & $\mathrm{I}(0)$ & $-5.5662^{\mathrm{b} * * *}$ & - & $\mathrm{I}(0)$ \\
\hline$U C_{t}^{e}$ & $-6.4738^{\mathrm{a} * * *}$ & - & $\mathrm{I}(0)$ & $-5.4662^{* * *}$ & - & $\mathrm{I}(0)$ \\
\hline$O P_{t}$ & $-2.2176^{\mathrm{b}}$ & $-9.6278^{\mathrm{b} * * *}$ & $\mathrm{I}(1)$ & $-1.4606^{\mathrm{b}}$ & $-8.9845^{\mathrm{b} * * *}$ & $\mathrm{I}(1)$ \\
\hline
\end{tabular}

Note: The exogenous lags are selected based on Schwarz info criteria, while ****,**,* imply that the series is stationary at $1 \%, 5 \%$ and $10 \%$ respectively. The superscript a\&b denotes model with constant and model with constant and trend, respectively.

\section{THE MODEL AND ESTIMATION PROCEDURE}

\section{Asymmetry monetary policy equation without uncertainty}

In attempt to validate or refute the earlier established theoretical foundations regarding the asymmetry effect of monetary policy, we employ an empirical framework similar to that given by Cover (1992). The framework which consists of two equations is often refers to as two-step procedure (see Gogas et al., 2018; Karras, 2013; Zakir and Malik, 2013; Tan et al., 2010, Karras, 1999; Ravn and Sola, 1996, among others). In the first step, we specify and estimate a monetary policy reaction function via the linear ARDL from which we generate both anticipated and unanticipated series of monetary policy shocks. Such a specification following a money supply process is given as follows:

$$
m_{t}={ }_{0}+{ }_{1} m_{t 1}+{ }_{2} \operatorname{intr}_{t 1}+{ }_{3} y_{t 1}+{ }_{4} e r_{t 1}+{ }_{5} \operatorname{infl}_{t 1}+{ }_{i=1}^{N 1}{ }_{i} m_{t 1}+{ }_{j=0}^{N 2} \operatorname{intr}_{t j}+{ }_{j=0}^{N 3}{ }_{j} y_{t j}+{ }_{j=0}^{N 4}{ }_{j} e r_{t j}+{ }_{j=0}^{N 5} \operatorname{infl}_{t j}+{ }_{t}^{m}
$$

The supply of money process specified in equation (1) conventionally assumed that $m$ which is log of money base or M2 is influenced by the level of income $(y)$ measured as log of output, interest rate (intr) measured as log of prime lending rate and inflation (infl) measured as log of consumer price index. The inclusion of exchange rate which is measured as log of Naira/USD is to capture the feature of the Nigerian economy as a small open economy (see also Olofin et al., 2014). The ${ }_{t}^{m}$ in equation (1) is the monetary policy shocks such that the unanticipated monetary policy shocks will be obtained as below:

$$
{ }_{t}^{m}=m_{t} \quad{ }_{0}+{ }_{1} m_{t 1}+{ }_{2} \operatorname{intr}_{t 1}+{ }_{3} y_{t 1}+{ }_{4} e r_{t 1}+{ }_{5} \operatorname{infl}_{t 1}+{ }_{i=1}^{N 1}{ }_{i} m_{t 1}+{ }_{j=0}^{N 2} \operatorname{intr}_{t j}+{ }_{j=0}^{N 3}{ }_{j} y_{t j}+{ }_{j=0}^{N 4}{ }_{j} e r_{t j}+{ }_{j=0}^{N 5} \operatorname{infl}_{t j}
$$

Note that in both equations (1) and (2), there are no decompositions of the unanticipated monetary policy shocks into positive (contractionary) or negative (expansionary) monetary policy; hence, the assumption of symmetric (linear) behaviour of monetary policy. The next 
step therefore, is to partition the unanticipated monetary policy shocks generated in equation (2) into positive (contractionary) and negative (expansionary) monetary policy shocks. These decomposed unanticipated monetary policy shocks are defined as follows:

$$
{ }_{t}^{+}=\max \left(\begin{array}{c}
m \\
t
\end{array}, 0\right)
$$

and

$$
{ }_{t}=\min \left(\begin{array}{c}
m \\
t
\end{array}, 0\right)
$$

where the series ${ }_{t}^{+}$equal the monetary policy shocks if the shock is positive, otherwise it equal zero, while the series ${ }_{t}$ equal monetary policy shocks if the shock is negative, otherwise it equals zero.

The second stage of our estimation procedure is to reflect the positive and negative monetary policy shock series in each of the macroeconomic equations under consideration namely, output; prices (inflation); and exchange rate equations. To achieve this, we follow the nonlinear ARDL (NARDL) which is considered to be less computationally intensive compared to other asymmetric models. More so, the NARDL approach to model asymmetric does not require identical order of integration [i.e. I(1)] for all series in the model. In the context of this study, the NADRL is given as:

$$
x_{t}={ }_{0}+{ }_{1} x_{t 1}+{ }_{1} z_{t 1}+{ }_{2} m p_{t 1}^{+}+{ }_{3} m p_{t 1}+{ }_{i=1}^{N 1} x_{t i}+{ }_{i=1}^{N 2}{ }_{i} z_{t i}+{ }_{j=0}^{N 3}\left({ }_{j}^{+} m p_{t j}^{+}+{ }_{j} m p_{t j}\right)+t_{t}
$$

where $m p_{t}^{+}={ }_{t}^{+}$for positive monetary policy shock and $m p_{t}={ }_{t}$ for negative monetary policy shock whereas $x=y$, denoting output growth and inflation rate, respectively. The asymmetry response of each of these policy goals will be singly analyze, while the term $z_{t}$ control for other factors in the model which may vary for each of the policy goals depending on their respective underlying hypothesis.

Starting with the output growth ( $y$ ) equation, we control for interest rate, inflation and exchange rate such that;

$$
\begin{gathered}
y_{t}={ }_{0}+{ }_{1} y_{t 1}+{ }_{1} \operatorname{intr}_{t 1}+{ }_{1} \operatorname{infl}_{t 1}+{ }_{1} e r_{t 1}+{ }_{2} m p_{t 1}^{+}+{ }_{3} m p_{t 1}+{ }_{i=1}^{N 1} y_{t i}+{ }_{i=1}^{N 2} i_{i} \operatorname{intr}_{t i}+ \\
{ }_{i=1}^{N 3} \operatorname{infl}_{t i}+{ }_{i=1}^{N 4} e r_{t i}+{ }_{j=0}^{N 5}\left(+_{j}^{+} m p_{t j}^{+}+{ }_{j} m p_{t j}\right)+{ }_{t}
\end{gathered}
$$

For estimating the output model in equation (4), we use log of industrial production which is more strongly identify with monetary policy impact on economic activity (see Lo and Piger, 2005). Using the word of Christiano et al. (1997), "the manufacturing sector tends to react to a greater extent to a monetary policy shock than economy-wide measure of output". Another feature of the model is that output also depends on its lagged value $\left(y_{t_{1}}\right)$.

For the price level (inflation) equation, we control for both the demand-side and supply-side pressures using output in the case of the formal and oil prices in the case of the latter. Being a small open economy, we also control for exchange rate pass-through in the price equation. Adopting an extended traditional Phillips curve approach to modeling inflation (see Salisu et al., 2018; Salisu and Isah, 2018; Tule et al., 208), the inflation equation in the context of this study is as shown below. 


$$
\begin{gathered}
{ }_{t}={ }_{0}+{ }_{1 t_{1}}+{ }_{1} y_{t 1}+{ }_{1} O p_{t 1}+{ }_{1} e r_{t 1}+{ }_{2} m p_{t 1}^{+}+{ }_{3} m p_{t 1}+{ }_{i=1}^{N 1}{ }_{i}+{ }_{i=1}^{N 2} y_{t i}+ \\
{ }_{i=1}^{N 3} \quad o p_{t i}+{ }_{i=1}^{N 4} e r_{t i}+{ }_{j=0}^{N 5}\left(+_{j}^{+} m p_{t j}^{+}+{ }_{j} m p_{t j}\right)+{ }_{t}
\end{gathered}
$$

where ${ }_{t}$ denoting inflation rate is measured as log of consumer price index, $y$ denoting output and $o p$ representing oil price proxies for demand-side and the supply-side of inflation, respectively. While the oil price is measured log Brent crude prices, the output and variables in the model remain as earlier defined.

\section{Asymmetry monetary policy shocks with uncertainty}

So far we have considered the probable asymmetry effects of monetary policy shocks mainly from the perspective of direction of policy action. Here, we test whether the expansionary monetary policy affects output and inflation differently as compared with a contractionary monetary policy shock. To account for the role internal and external uncertainties as potential accelerator of asymmetry effects of monetary policy shock, we extend and modify the conventional monetary process in equation (1) as follows:

$$
\begin{aligned}
m_{t}^{u}= & { }_{0}+{ }_{1} m_{t 1}+{ }_{2} \operatorname{intr}_{t 1}+{ }_{3} y_{t 1}+{ }_{4} e r_{t 1}+{ }_{5} \operatorname{infl}_{t 1}+{ }_{6} u c_{t 1}+{ }_{i=1}^{N 1}{ }_{i} m_{t 1}+{ }_{j=0}^{N 2} \operatorname{intr}_{t j}+{ }_{j=0}^{N 3}{ }_{j} y_{t j}+{ }_{j=0}^{N 4} j_{j} e r_{t j}+ \\
& { }_{j=0}^{N 5} \operatorname{infl}_{t j}+{ }_{j=0}^{N 6} u c_{t j}+{ }_{t}^{m u}
\end{aligned}
$$

Motivated by the earlier established assertion that monetary policy is made in an environment of substantial uncertainty (see Monte, 2010), the additional term in the extended supply of money process in equation (6) for instance $u c_{t}$ reflects both internal and external uncertainties each of which will be singly analyze in this regard. Consequently, the superscript term (i.e. $u$ ) in the specification is suggesting that the supply of money process in this instance is taken cognizance of the uncertainty feature of environment in where the monetary is being formulated. Hence, the unanticipated monetary policy shocks to be generated from the above linear ARDL specification will be infused by the variability of government borrowing as a measure for internal uncertainty and variability of oil prices as a measure for external uncertainty. The government borrowing can affect the monetary policy, particularly, in the perspective of developing countries where governments borrow extensively from their central banks to finance their fiscal deficits thus justifying its suitability to capture the vulnerability of monetary authorities to political pressure. The variability of international oil prices is rather a commonplace knowledge; however, its choice as a measure of external uncertainty in the context of this study is mainly informed by the oil-dependent feature of the investigated economy.

Stemming from equation and similar to equation (3), the unanticipated monetary policy shocks with the role of uncertainty will be generated from the extended supply of money process in equation (6) as follows:

$$
\begin{aligned}
{ }_{t}^{m u}= & m_{t}^{u} \quad{ }_{0}+{ }_{1} m_{t 1}+{ }_{2} \operatorname{intr}_{t 1}+{ }_{3} y_{t 1}+{ }_{4} e r_{t 1}+{ }_{5} \operatorname{infl} l_{t 1}+{ }_{6} u c_{t 1}+{ }_{i=1}^{N 1}{ }_{i} m_{t 1}+{ }_{j=0}^{N 2}{ }_{j} \operatorname{intr}_{t j}+{ }_{j=0}^{N 3}{ }_{j} y_{t j}+{ }_{j=0}^{N 4} j_{j} e r_{t j}+ \\
& \quad{ }_{j=0}^{N 5} \operatorname{infl}_{t j}+{ }_{j=0}^{N 6} u c_{t j}
\end{aligned}
$$


Similar to the earlier procedure, we decomposed the uncertainty -based unanticipated monetary policy shocks into positive (contractionary) or negative (expansionary) monetary policy as follows:

$$
{ }_{t}^{u+}=\max \left(\begin{array}{c}
m u \\
t
\end{array}, 0\right)
$$

and

$$
{ }_{t}^{u}=\min \left(\begin{array}{c}
m \\
t
\end{array}, 0\right)
$$

where the series ${ }_{t}^{u+}$ equal the monetary policy shocks with the role of uncertainty if the shock is positive, otherwise it equal zero, while the series ${ }_{t}^{u}$ equal monetary policy shocks with the role of uncertainty if the shock is negative, otherwise it equals zero. We then proceed on to reflect the positive and negative uncertainty -based monetary policy shock series in each of the NARDL specification for output and inflation similar to those in equations $4 \& 5$. In this case $m p \_u_{t}^{+}={ }_{t}^{u+}$ for positive uncertainty -based monetary policy shock and $m p{ }_{-} u_{t}={ }_{t}^{u}$ for negative uncertainty -based monetary policy shock.

Again, the uncertainty -based asymmetry response of each of the policy goals namely, output growth and inflation will be singly analyzed in their respective equations. For the purpose of clarity, we further demonstrate the probable asymmetry response of output growth to uncertainty -based monetary policy shocks as below.

$$
\begin{gathered}
y_{t}={ }_{0}+{ }_{1} y_{t 1}+{ }_{1} \operatorname{intr}_{t 1}+{ }_{1} \operatorname{infl}_{t 1}+{ }_{1} e r_{t 1}+{ }_{2} m p \quad u_{t 1}^{+}+{ }_{3} m p u_{t 1}+{ }_{i=1}^{N 1} y_{t i}+{ }_{i=1}^{N 2}{ }_{i} \operatorname{intr}_{t i}+ \\
{ }_{i=1}^{N 3} \quad \operatorname{infl}_{t i}+{ }_{i=1}^{N 4} e r_{t i}+{ }_{j=0}^{N 5}\left({ }_{j}^{+} m p u_{-} u_{t j}^{+}+{ }_{j} m p u_{t j}\right)+{ }_{t}
\end{gathered}
$$

and for price level equation, the probable asymmetry response of inflation to uncertainty based monetary policy shock is as follows:

$$
\begin{aligned}
& { }_{t}={ }_{0}+{ }_{1 t_{1}+}+{ }_{1} y_{t 1}+{ }_{1} o p_{t 1}+{ }_{1} e r_{t 1}+{ }_{2} m p_{-} u_{t 1}^{+}+{ }_{3} m p_{-} u_{t 1}+{ }_{i=1}^{N 1}{ }_{i}{ }_{t i}+{ }_{i=1}^{N 2} y_{t i}+ \\
& { }_{i}^{N 3} \quad o p_{t i}+{ }_{i=1}^{N 4} i e r_{t i}+{ }_{j=0}^{N 5}\left({ }_{j}^{+} m p_{-} u_{t j}^{+}+{ }_{j} m p_{-} u_{t j}\right)+{ }_{t}
\end{aligned}
$$

It must be pointed out that all the control variables as applicable in each of the equations, namely equations \& 9 remain as earlier defined. The concern here is to test whether the uncertainties both from internal and/or external source accelerate the extent to which expansionary monetary policy shock affects output and inflation differently as compared with a contractionary monetary policy shock.

\section{EMPIRICAL RESULTS}

We commence our empirical analysis to examine the accuracy of the estimated supply of money process. The essence is to determine the fit of the models in order to ascertain the accuracy of the anticipated monetary policy generates from the process. Of interest to us at this juncture is the post estimation results associated with the various money supply process. As shown in Table 1 below, first, we estimate the money supply process without the role uncertainty and subsequently extend the process to include internal and external uncertainties. 
Deekor, L. L. N. (2019). Impact of Monetary Policy Shocks on Macroeconomic Fundamentals: The Role of Asymmetry and Uncertainty in Nigeria. Advances in Social Sciences Research Journal, 6(11) 110-129.

Table 1: Money Supply Estimates to Generate Unanticipated Monetary Policy Shocks

\begin{tabular}{|c|c|c|c|c|c|c|c|c|c|}
\hline \multirow[t]{2}{*}{ Parameter } & \multirow{2}{*}{\multicolumn{3}{|c|}{$\begin{array}{l}\text { Money supply process } \\
\text { without uncertainty }\end{array}$}} & \multicolumn{6}{|c|}{ Money supply process with uncertainty } \\
\hline & & & & \multicolumn{3}{|c|}{ Internal uncertainty } & \multicolumn{3}{|c|}{ External uncertainty } \\
\hline$C$ & \multirow{2}{*}{\multicolumn{3}{|c|}{$\begin{array}{c}0.0499(0.3806) \\
0.0499^{* * *}(0.0395)\end{array}$}} & \multicolumn{3}{|c|}{$0.0813(0.3744)$} & \multicolumn{3}{|c|}{$0.0370(0.3830)$} \\
\hline$m_{t 1}$ & & & & & & & & & \\
\hline$m_{t 1}^{u i}$ & \multicolumn{9}{|c|}{$-0.1369^{* * *}(0.0391)$} \\
\hline$m_{t 1}^{u e}$ & \multicolumn{9}{|c|}{$-0.1225^{* * *}(0.0400)$} \\
\hline$y_{t}$ & \multicolumn{3}{|c|}{$0.14681(0.1015)$} & \multicolumn{3}{|c|}{$0.1098(0.1009)$} & \multicolumn{3}{|c|}{$0.1476(0.1018)$} \\
\hline intr & \multicolumn{3}{|c|}{$-0.1392 * *(0.0576)$} & \multicolumn{3}{|c|}{$-0.1586^{* * *}(0.0572)$} & \multicolumn{3}{|c|}{$-0.1358^{* *}(0.0583)$} \\
\hline$t$ & \multicolumn{3}{|c|}{$0.0154(0.0317)$} & \multicolumn{3}{|c|}{$0.0074(0.0313)$} & \multicolumn{3}{|c|}{$0.0124(0.0326)$} \\
\hline$e r_{t}$ & \multicolumn{3}{|c|}{$0.0827^{* * *}(0.0268)$} & \multicolumn{3}{|c|}{$0.1072^{* * *}(0.0282)$} & \multicolumn{3}{|c|}{$0.0827^{* * *}(0.0629)$} \\
\hline$u c_{t}^{i}$ & \multicolumn{9}{|c|}{$3.4890^{* *}(1.0911)$} \\
\hline$u c_{t}^{e}$ & & & & & & & \multicolumn{3}{|c|}{$-0.2402(0.5838)$} \\
\hline \multirow[t]{2}{*}{ F-Bound Test } & F-stat & $\mathrm{I}(0)$ & $\mathrm{I}(1)$ & F-stat & $\mathrm{I}(0)$ & $\mathrm{I}(1)$ & F-stat & $\mathrm{I}(0)$ & $\mathrm{I}(1)$ \\
\hline & 7.25 & 2.39 & 3.38 & 7.30 & 2.27 & 3.28 & 6.32 & 2.27 & 3.28 \\
\hline$y_{t}$ & \multicolumn{3}{|c|}{$1.1767(0.8340)$} & \multicolumn{3}{|c|}{$0.8019(0.7382)$} & \multicolumn{3}{|c|}{$1.2048(0.8572)$} \\
\hline intr $_{t}$ & \multicolumn{3}{|c|}{$-1.1162^{* * *}(0.4013)$} & \multicolumn{3}{|c|}{$-1.1583^{* * *}(0.3629)$} & \multicolumn{3}{|c|}{$-1.1090^{* * *}(0.4097)$} \\
\hline 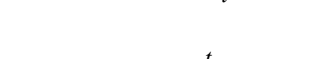 & \multicolumn{3}{|c|}{$0.1240(0.2367)$} & & $45(0.22$ & & & $15(0.25$ & \\
\hline$e r_{t}$ & 0.6 & ${ }^{* * *}(0.2$ & & 0.78 & *** $(0.2$ & & & $52^{* *}(0.2$ & 07) \\
\hline$u c_{t}^{i}$ & & & & 5.67 & $8^{* *}(2.7$ & & & & \\
\hline$u c_{t}^{e}$ & & & & & & & & $611(4.8$ & \\
\hline $\operatorname{adj} R^{2}$ & & 0.97 & & & 0.98 & & & 0.98 & \\
\hline & & ost est & tion/ & nostic t & t resul & & & & \\
\hline$L B(2)$ & & $7^{* *}(0.6$ & & & $80(0.1$ & & & $155(0.0$ & \\
\hline$L B^{2}(2)$ & & $27(0.6$ & & & $59(0.6$ & & & $676(0.6$ & \\
\hline ARCH LM (2) & & $67(0.6$ & & & $89(0.6$ & & & $898(0.6$ & \\
\hline
\end{tabular}

Note: The subscripts $u^{i} \& u^{e}$ denote money supply process with internal and external uncertainty, respectively. Similarly, the parameters $u c^{i}$ and $u c^{e}$ capture coefficients on internal and external uncertainty, respectively. The ARCH LM tests refer to the Engle (1982) test for conditional heteroscedasticity, the LB and LB2 imply the Ljung-Box tests for autocorrelations involving the standardized residuals in levels and squared standardized residuals, respectively, while the Reset test is Ramsey Reset test for linearity of the model. The values in parenthesis are standard error for the estimates but probability value for the post estimation tests. ${ }^{* * *}, * *$ and ${ }^{*}$ denote $1 \%, 5 \%$ and $10 \%$ levels of significance.

Supporting the appropriateness of the various estimated money supply process is the substantial evidence of no serial correlation and heteroscedasticity nonetheless the model with or without the role uncertainty. To put it differently, all the Q-stat values particularly the squared ones as well as the ARCH LM F-stat are insignificant with large p-values. In addition to our confirmation of the fit of the estimated linear ARDL models for each of the money supply process under consideration, the F-stat for the Bound test also confirmed the long run property of the models at 5\% level of significance. To corroborate this information of long run relationship and goodness of fit of the models, we also perform CUSUM and CUSUMQ stability tests. A look at Figure 1 show that each test is within the five per cent critical bound thus affirming the stability of the models. 
Figure 1: Stability test results for money supply process

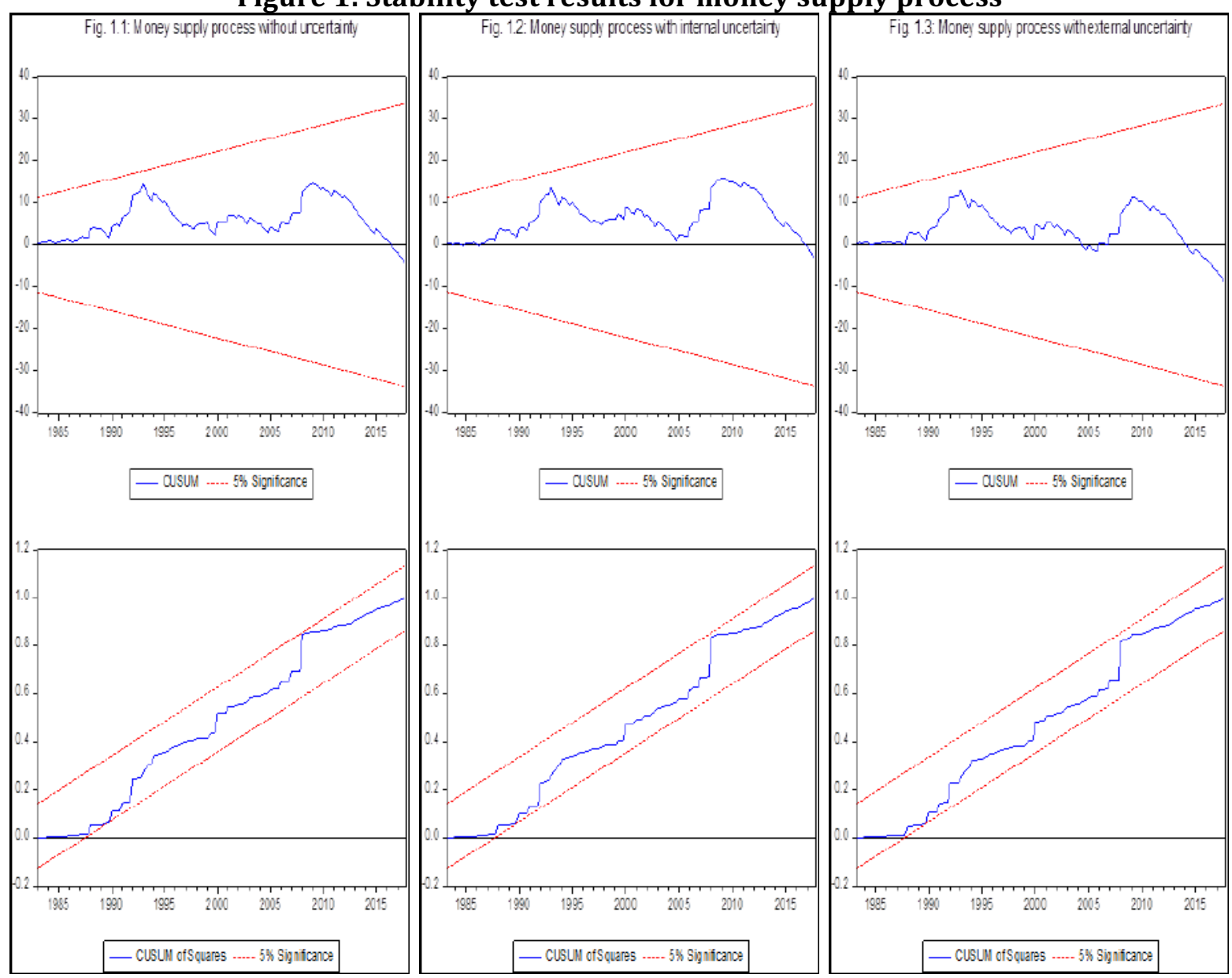

Haven ascertain the appropriateness of the models; we then, proceed on to generate the measure for unanticipated monetary policy shocks as applicable to the residuals of the models (see Figure 2). However, the fact that the coefficient on uncertainty is only significant when the measure is internal suggests that the potential of uncertainty to accelerate the asymmetric effects of monetary policy is mainly internal. Henceforth, discuss on the extent to which uncertainty matters in the asymmetry effects of monetary policy will only be from the perspective of political pressure via the variability of government borrowing (internal uncertainty). 
Figure 2: The unanticipated monetary policy shocks from money supply process

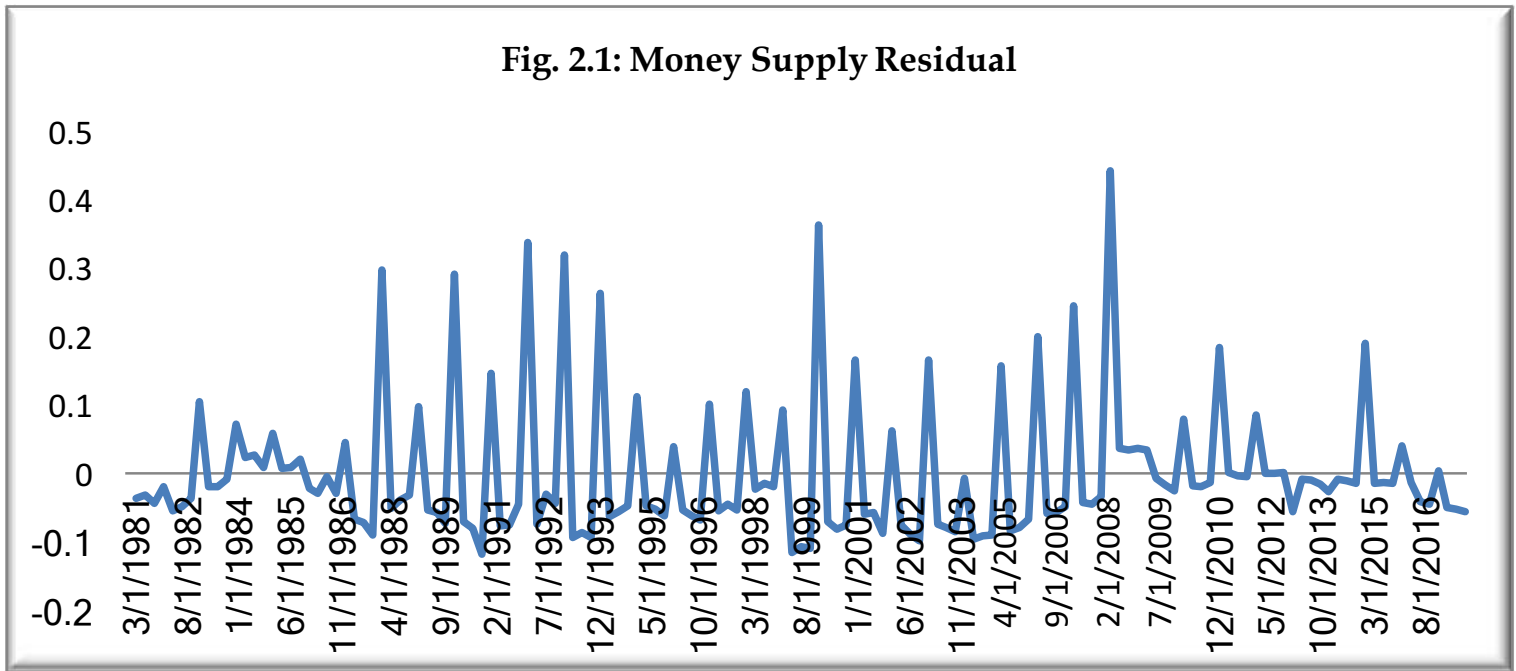

Fig. 2.2: Money supply residual with uncertainty due to variability in fiscal borrowing

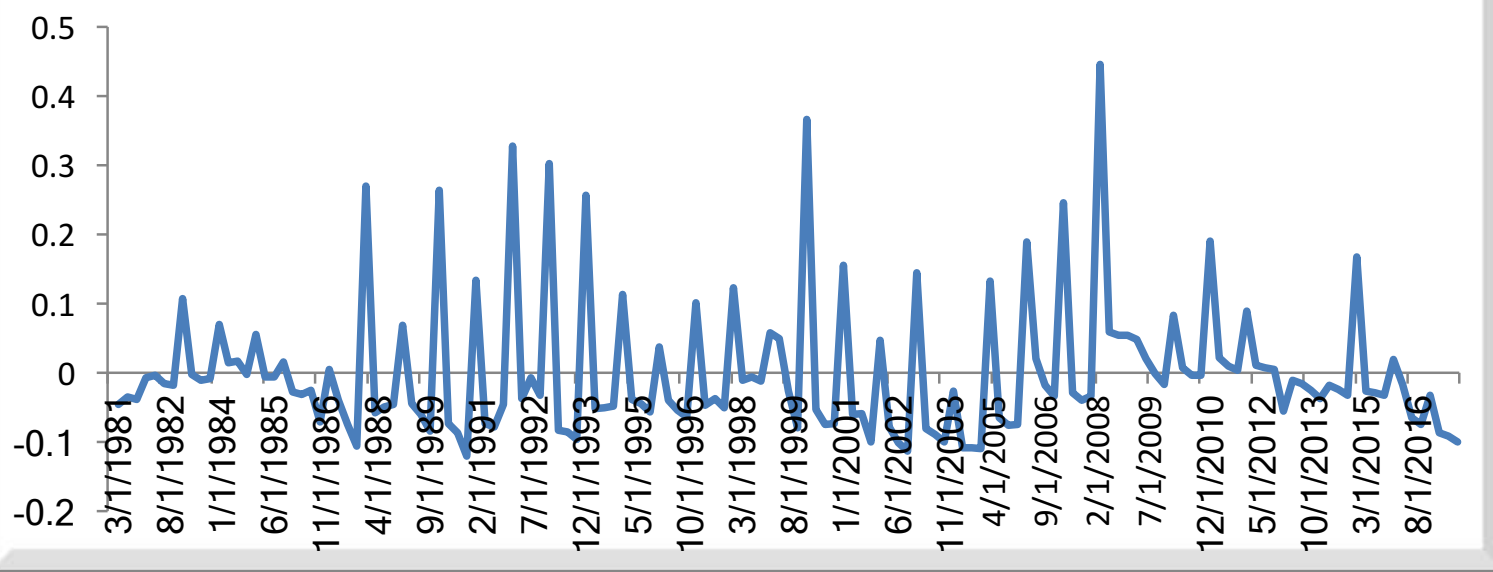

\section{Empirical results for asymmetry effects of monetary policy}

One of the main objectives of this study is to test the asymmetry effects of monetary policy on aggregates such as output growth and inflation rate. To achieve this, we partition the unanticipated monetary shocks obtained from the estimated money supply process into positive (contractionary) and negative (expansionary) monetary policy shocks (see Figure 3).

Figure 3: Unanticipated Asymmetry Monetary Policy Shocks from Money Supply Process

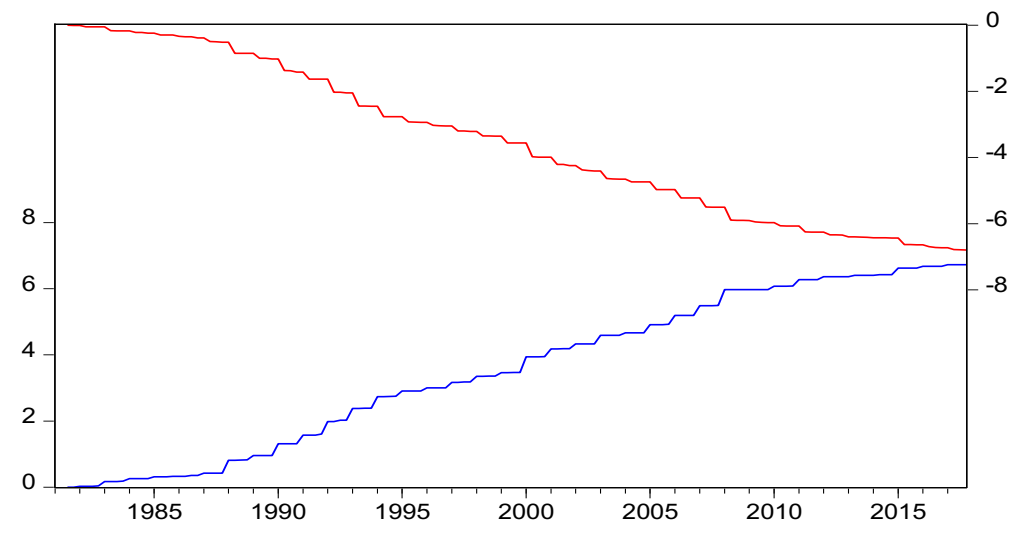


Thus, we would follow the earlier lay down estimation procedures in the immediate preceding section of this paper to include the positive and negative partial sum decomposition of the monetary policy shock series in figure 3 in output and inflation models. The essence here is to determine whether these policy goals respond asymmetrically to monetary policy shocks in Nigeria. Essentially, we employ the Wald restriction test to ascertain the significance of asymmetry effects of monetary policy on output and inflation. For the Wald test, the null hypothesis of no asymmetries - $H_{0}:{ }_{2}={ }_{3}$ (for long run) and $H_{0}:{ }_{j=0}^{n}{ }_{j}^{+}={ }_{j=0}^{m} \quad$ (for short run) is tested against the alternative of presence of asymmetries $-H_{1}:{ }_{2} \quad{ }_{3}$ (for long run) and $H_{1}:_{j=0}^{n}{ }_{j}^{+}{ }_{j=0}^{m} \quad$ (for short run).

Table 2: NARDL Estimates on Asymmetry Effects of Monetary Policy from Money supply process

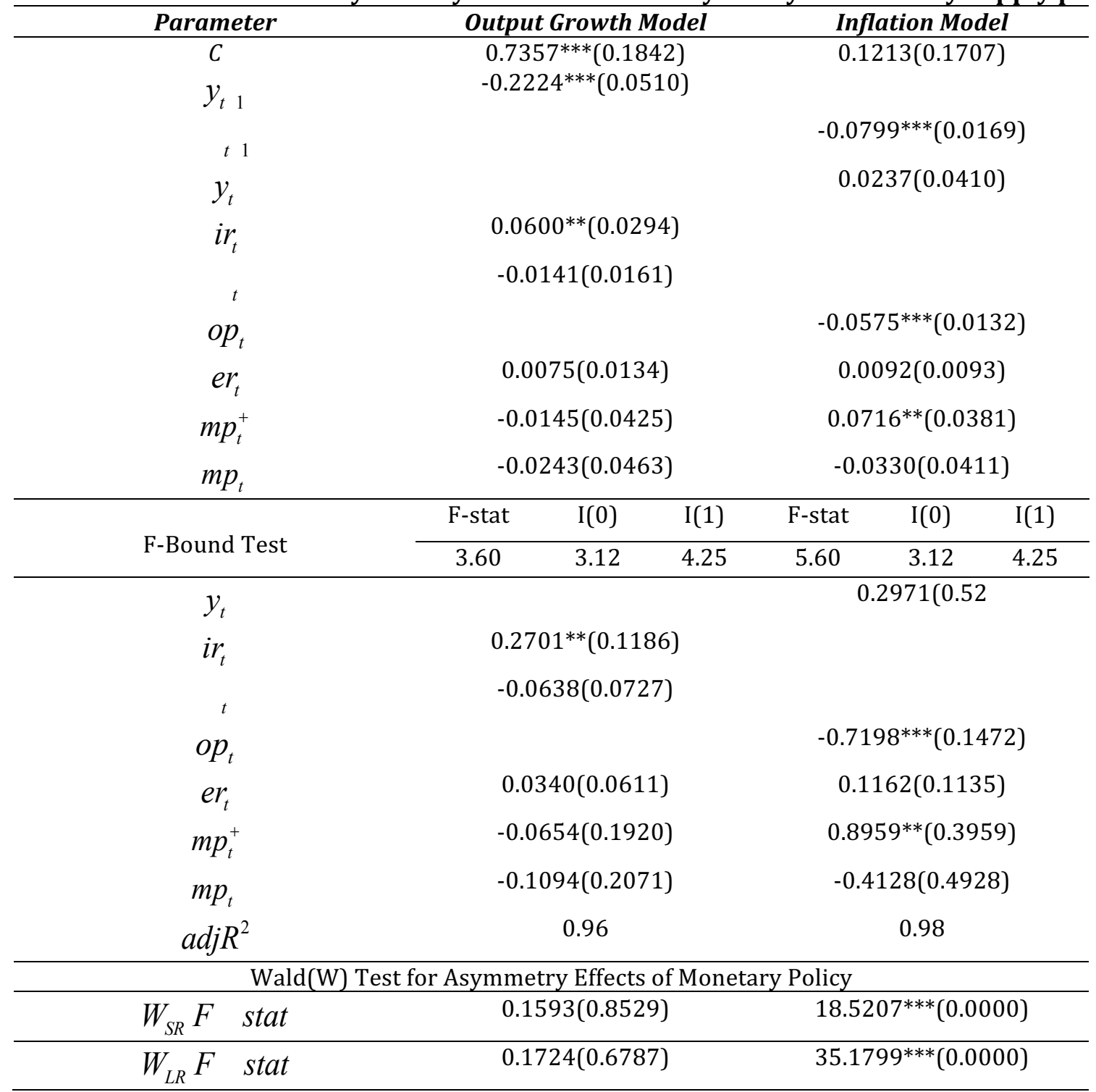

Note: The term W represents Wald restriction test distributed as distributed as (5) while subscripts SR \& LR denote short run and long run situations. The values in parenthesis are standard error for the estimates but probability value for the Wald restriction test, while ${ }^{* * *},{ }^{* *}$ and ${ }^{*}$ denotes $1 \%, 5 \%$ and $10 \%$ levels of significance. 
A look at Table 2 seems to be suggesting that the effectiveness of monetary policy to affect output and inflation is only statistically viable or significant in the case of the latter. However, the said significant response of inflation to monetary policy shocks tend to vary for contractionary and expansionary monetary policy shocks thus given credence to the New Keynesian macroeconomic models which predict that monetary shocks have asymmetric effects on inflation. For instance, our findings show that inflation respond more and significantly to positive monetary shocks than to negative shocks. We further explore Wald restriction test to confirm the significance of such asymmetry effect of monetary policy and test result consistently suggest that the asymmetry holds both in the short and long run situation.

\section{Does uncertainty matter for the asymmetry effects of monetary policy}

Our hypothesis of uncertainty as potential source of asymmetries in monetary policy was original described from both internal and external perspectives. But for the insignificant of the latter in the estimated money supply process, the extent to which uncertainty matters in the asymmetry effects of monetary was mainly examined via the internal source of uncertainty. Essentially, we extend our conventional money supply process to include the measure for internal uncertainty such variability in government borrowing to capture whether political pressure from the fiscal side of the economy matter for the asymmetry effects of monetary policy.

In what appears to be consistent with our earlier findings in the model without uncertainty, the empirical results in Table 3 indicate the effectiveness of monetary policy to affect the target aggregates as only significant in the case of inflation. Similarly, we find the significant response of inflation to monetary shocks to vary for positive and negative monetary shocks nonetheless the role of uncertainty in the money supply process. In addition to the significance of such asymmetry effect of monetary shock as suggested by the statistically significance of the Wald test, quite an interesting finding is the relatively higher magnitude of the asymmetry effect when the model is extended to include the role of uncertainty. That is, compared to the empirical results in table 2, where the coefficients on positive monetary shock in the inflation model are 0.071 and 0.895 for short and long run situation respectively. The magnitude of the coefficients are however, 0.074 and 0.903 when uncertainty such as variability in government borrowing is reflected in the model thus confirming the potential political pressure from the fiscal side to accelerate the asymmetry effect of monetary policy. 
Table 3: NARDL Estimates on the Role of Uncertainty in Asymmetry Effects of Monetary Policy with the

\begin{tabular}{|c|c|c|c|c|c|c|}
\hline Parameter & \multicolumn{3}{|c|}{ Output Growth Model } & \multicolumn{3}{|c|}{ Inflation Model } \\
\hline$C$ & \multicolumn{3}{|c|}{$0.7410(0.1849)$} & \multicolumn{3}{|c|}{$0.1555(0.9101)$} \\
\hline$y_{t 1}$ & \multicolumn{3}{|c|}{$-0.2244^{* * *}(0.0514)$} & \multirow{2}{*}{\multicolumn{3}{|c|}{$-0.0820^{* * *}(0.0167)$}} \\
\hline$t 1$ & & & & & & \\
\hline$y_{t}$ & & & & \multicolumn{3}{|c|}{$0.0154(0.0409)$} \\
\hline intr $_{t}$ & \multicolumn{3}{|c|}{$0.0617^{* *}(0.0291)$} & & & \\
\hline$t$ & \multicolumn{3}{|c|}{$-0.0152(0.0162)$} & & & \\
\hline$o p_{t}$ & & & & \multicolumn{3}{|c|}{$-0.0571^{* * *}(0.0128)$} \\
\hline$e r_{t}$ & & & & \multicolumn{3}{|c|}{$0.0119(0.0092)$} \\
\hline$m p_{t}^{u+}$ & \multicolumn{3}{|c|}{$-0.0089(0.0433)$} & \multicolumn{3}{|c|}{$0.0740^{* *}(0.0389)$} \\
\hline$m p_{t}^{u}$ & \multicolumn{3}{|c|}{$-0.0233(0.0494)$} & \multicolumn{3}{|c|}{$-0.0414(0.0431)$} \\
\hline \multirow[b]{2}{*}{ F-Bound Test } & F-stat & $\mathrm{I}(0)$ & $\mathrm{I}(1)$ & F-stat & $\mathrm{I}(0)$ & $\mathrm{I}(1)$ \\
\hline & 3.60 & 3.12 & 4.25 & 5.93 & 3.12 & 4.25 \\
\hline$y_{t}$ & & & & \multicolumn{3}{|c|}{$0.1879(0.5048)$} \\
\hline intr $_{t}$ & \multicolumn{3}{|c|}{$0.2749 * *(0.1157)$} & & & \\
\hline$t$ & \multicolumn{3}{|c|}{$-0.0680(0.0726)$} & & & \\
\hline$o p_{t}$ & & & & \multicolumn{3}{|c|}{$-0.6974^{* * *}(0.1411)$} \\
\hline$e r_{t}$ & \multicolumn{3}{|c|}{$0.0333(0.0596)$} & \multicolumn{3}{|c|}{$0.1461(0.1071)$} \\
\hline$m p_{t}^{u+}$ & \multicolumn{3}{|c|}{$-0.0400(0.1938)$} & \multicolumn{3}{|c|}{$0.9032^{* *}(0.4184)$} \\
\hline$m p_{t}^{u}$ & \multicolumn{3}{|c|}{$-0.1039(0.2187)$} & \multicolumn{3}{|c|}{$-0.5059(0.5032)$} \\
\hline $\operatorname{adj} R^{2}$ & \multicolumn{3}{|c|}{0.96} & \multicolumn{3}{|c|}{0.98} \\
\hline \multicolumn{7}{|c|}{ Wald(W) Test for Asymmetry Effects of Monetary Policy } \\
\hline$W_{S R} F \quad$ stat & \multicolumn{3}{|c|}{$0.2949(0.5880)$} & \multicolumn{3}{|c|}{$20.0432^{* * *}(0.0000)$} \\
\hline$W_{L R} F \quad$ stat & \multicolumn{3}{|c|}{$0.3120(0.5773)$} & \multicolumn{3}{|c|}{$37.5317^{* * *}(0.0000)$} \\
\hline
\end{tabular}

Note: The term $W$ represents Wald restriction test distributed as distributed as (5) while subscripts SR \& LR denote short run and long run situations. The values in parenthesis are standard error for the estimates but probability value for the Wald restriction test, while ***,** and ${ }^{*}$ denote $1 \%, 5 \%$ and $10 \%$ levels of significance.

\section{Robustness Check}

As earlier established in the introductory section of this study, there are two main approaches to measure or evaluate monetary policy shocks namely, money supply process and/or the interest rate channel. So far, we have only considered the money supply process which has been the common practice in the literature. That is, quite a reasonable number of the extant studies rather use one of the approaches and none to the best of our knowledge has considered both in their study. In the context of this study however, we further subject our finding to robustness check such as whether the asymmetry response of the policy variables is sensitive to the choice of indicator/measure of monetary policy shocks. Thus, in an additional to the money supply process, we would be considering the interest rate channel to generate an alternative unanticipated monetary policy shocks. 
However, for the sake of consistent and fair comparison, all the estimation procedures as already demonstrated in the case of money supply process remain as defined, but the unanticipated monetary policy shock. Essentially, we follow the Taylor's rule to hypothesis that monetary policy instrument is based on short-term nominal interest rate (Monetary Policy Rate (MPR) in the case of Nigeria), and that the Central Bank sets this instrument in order to achieve a target level for inflation. It may also react to deviations of output from equilibrium. Therefore, interest rate is a function of output gap, exchange rate and MPR. Exchange rate is included in this equation because we are not sure whether uncovered interest parity holds in the case of Nigeria (see Olofin et al., 2014).

$i_{t}={ }_{1} y_{t}^{g}+{ }_{2}{ }_{t}^{e}+{ }_{3} e r+{ }_{4} m p r_{t}+{ }_{t}^{i}$

where $i$ is nominal interest rate using log of prime lending rate as earlier defined, while $y_{t}^{g}=\log \left(y_{t} / \bar{y}_{t}\right)$ such that $y_{t}$ is the actual output proxied by industrial production index and $\bar{y}_{t}$ is the potential output measured using the Hodrick Prescott Filter. ${ }_{t}^{e}$ is expected inflation in period $t+1$ given information at time $t$ and the exchange rate (er) remains as earlier defined. Similar to the money supply process in equation (1), of interest to us in the interest rate model in equation (10) is the residual term captured. It is instructive that of main interest to us in the interest rate model in equation (10) is the residual term $\left(\begin{array}{c}i \\ t\end{array}\right)$ such that the unanticipated monetary policy shocks would be obtained as follows:

$$
{ }_{t}^{i}=i_{t} \quad{ }_{1} y_{t}^{g}+{ }_{2}{ }_{t}^{e}+{ }_{3} e r+{ }_{4} m p r
$$

Consequently, the procedure for generating the uncertainty -based unanticipated monetary policy shock from the residuals of interest rate models with internal and external uncertainties is similar to that of equation (7) but following interest rate channel in this case. Thus, presented in Table 4 is the empirical estimate from the interest rate models with and without uncertainty.

Table 4: Interest Rate Estimates to Generate Unanticipated Monetary Policy Shocks

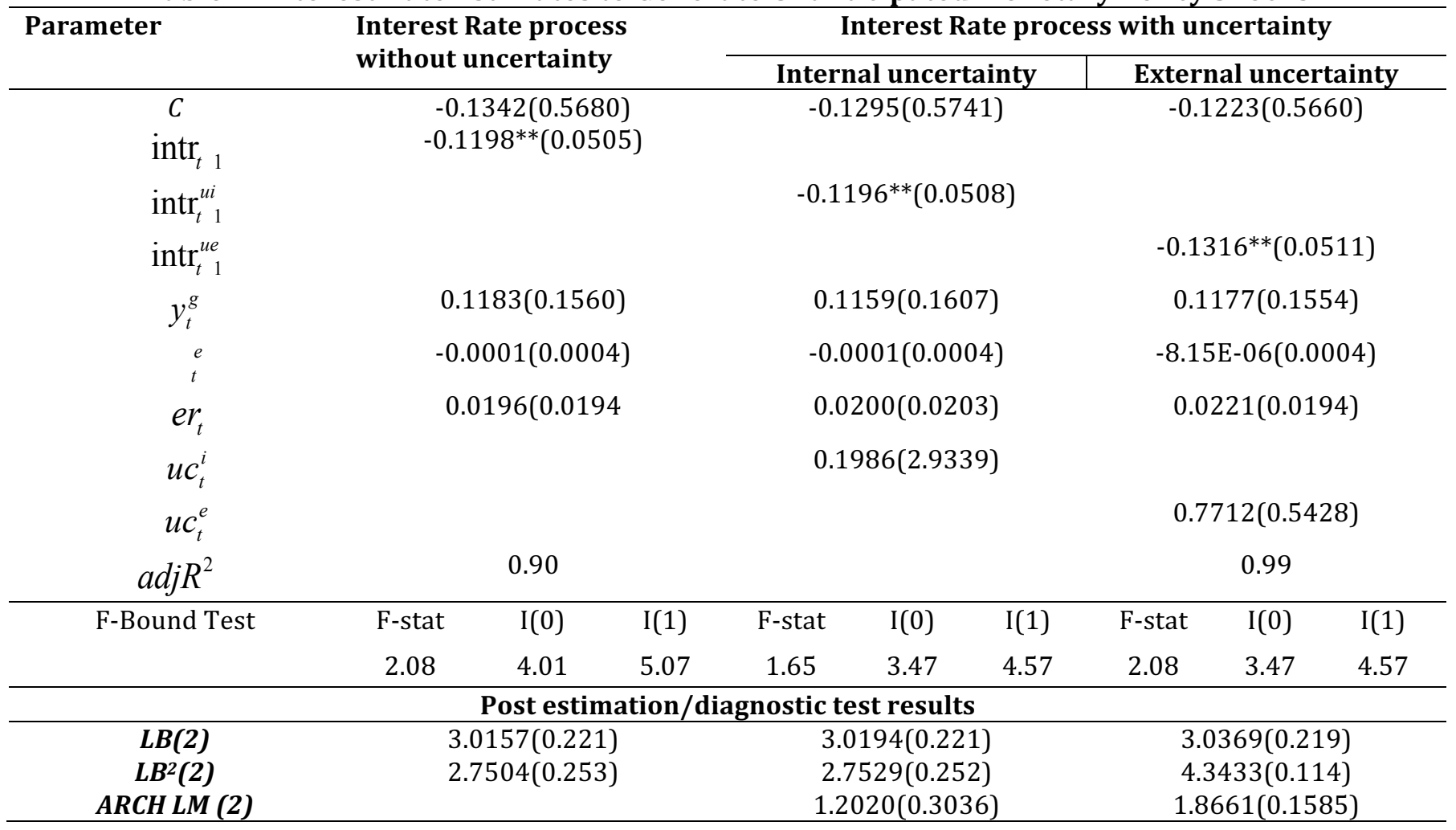


Note: The subscripts $u^{i} \& u^{e}$ denote interest rate process with internal and external uncertainty, while $u c^{i}$ and $u c^{e}$ capture coefficients on internal and external uncertainty, respectively. The ARCH LM tests refer to the Engle (1982) test for conditional heteroscedasticity, the LB and LB2 imply the Ljung-Box tests for autocorrelations involving the standardized residuals in levels and squared standardized residuals, respectively, while the Reset test is Ramsey Reset test for linearity of the model. The values in parenthesis are standard error for the estimates but probability value for the post estimation tests. ${ }^{* * *},{ }^{* *}$ and ${ }^{*}$ denote $1 \%, 5 \%$ and $10 \%$ levels of significance.

Relative to the money supply process, a look at table 4 show that the interest rate channel has no long run property. For instance, the computed F-statistics from the Bound co-integration test appears to be underneath the lower and upper bounds critical value. Supporting this position is the stability test in Figure 4 where each test namely, CUSUM and CUSUMQ fail to remain within the five per cent critical bound at least in some instances. Also, the statistically insignificant nature of the coefficient on uncertainty both from the internal and external sources is an indication that the potential of uncertainty accelerate the asymmetry effect of monetary policy may be sensitive to the choice of monetary policy indicator.

Figure 4: Stability test for interest rate process

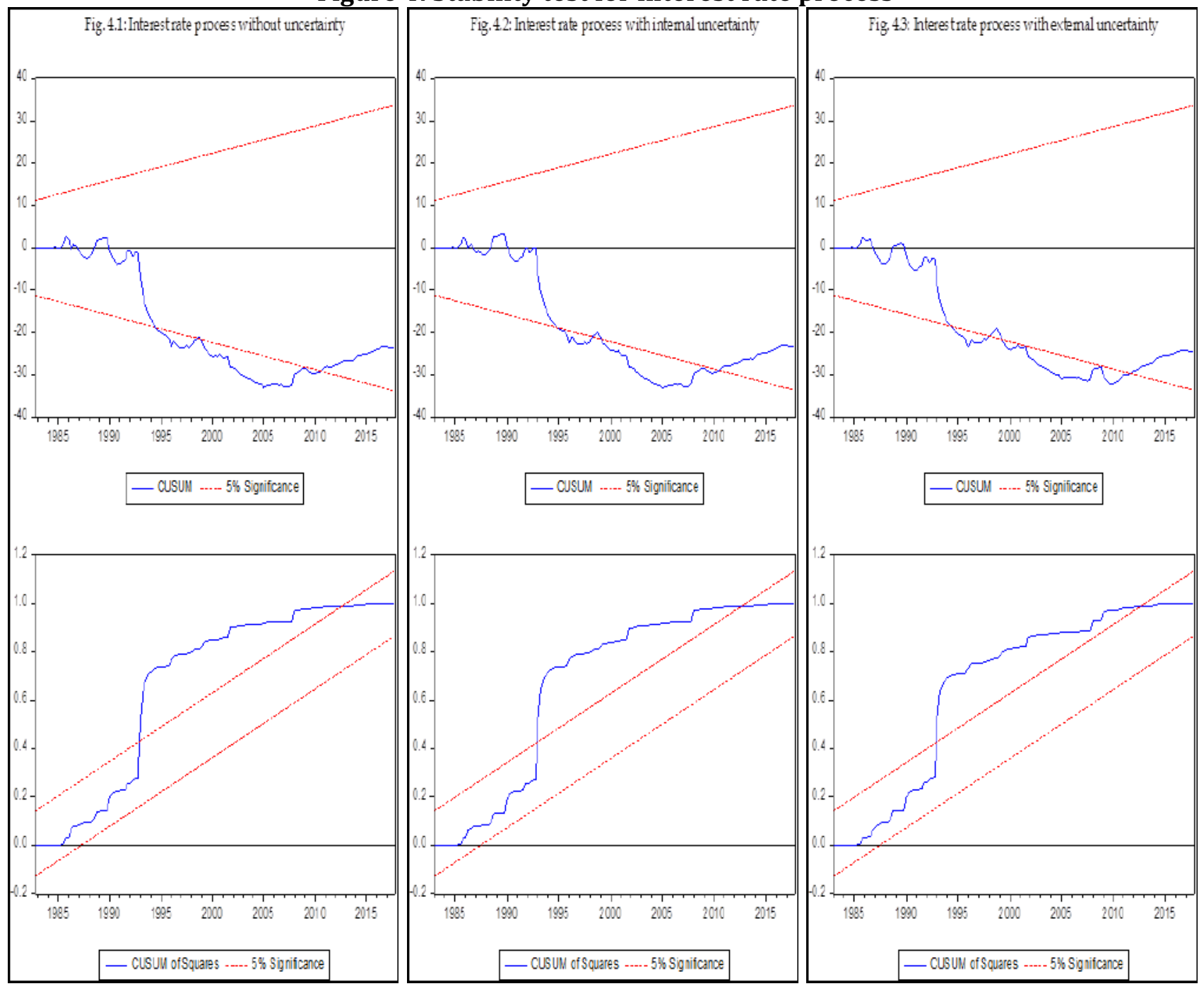

On the whole, the effectiveness of the obtained monetary shocks from the interest rate process as depicted in Figure 5 would be tested mainly on the short term dynamics of the policy 
variables (i.e. Output and inflation). Also, unlike the money supply process, the insignificant of the coefficient on uncertainty in the interest rate process means that the potential of the uncertainty to accelerate the asymmetry effect of monetary shock will not be considered in this regard.

Figure 5: The unanticipated monetary policy shocks from interest rate process

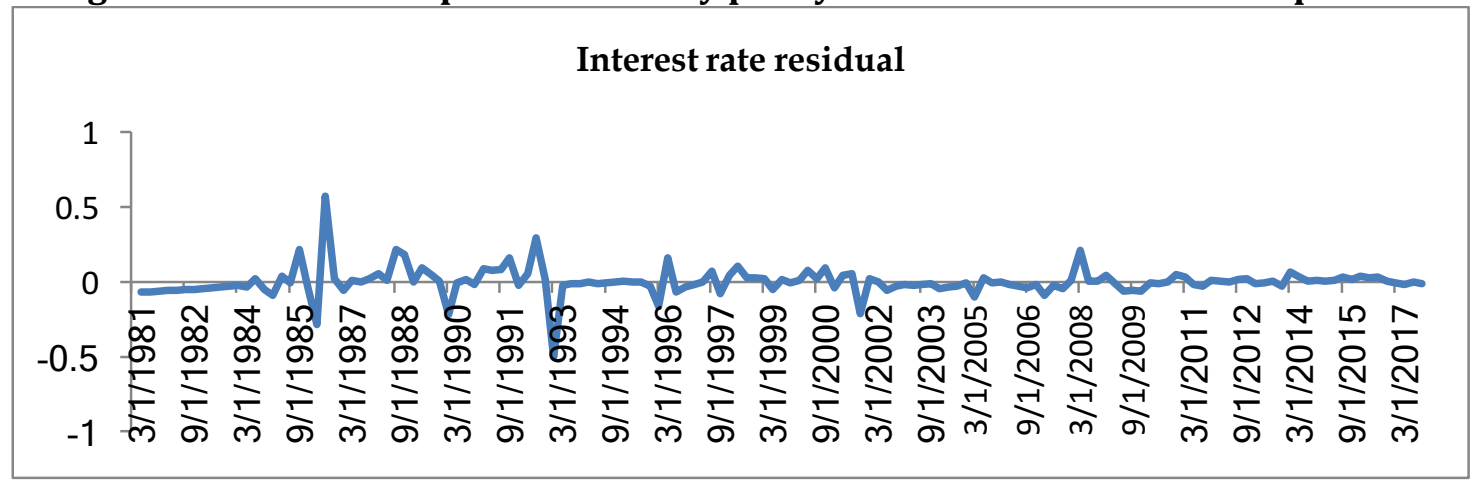

Keeping to the main objective of this study which is to test the asymmetry effect of monetary shocks, particularly within the context of exogenous environment, we further partition the interest rate -based unanticipated monetary shocks into positive (contractionary) and negative (expansionary) monetary shocks. The decomposed unanticipated monetary policy shocks are depicted in the figure below.

Figure 6: Unanticipated Asymmetry Monetary Policy Shocks from Interest Rate Process

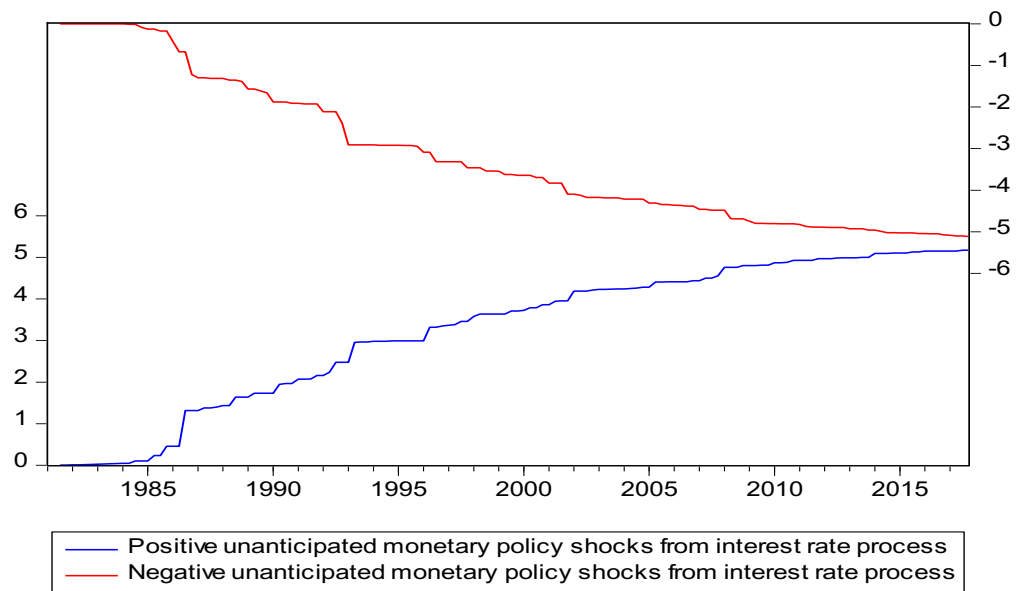

Suggesting the likelihood of the effectiveness as well as asymmetry effect of monetary policy to be sensitive to the choice of monetary policy indicator is the empirical results in Tables. Contrary to the money supply process where we find the effectiveness of monetary to affect policy goals as mainly evident in the case of inflation, the reverse appears to be the case in the case of interest rate process. We also find that, compared with the money supply process where inflation tends to respond differently to positive and negative monetary shocks, the output response to monetary shock is though significant but indifferent to positive or negative shocks. What this portends is that, while monetary shocks either positive or negative has no significant impact on output when the shocks are introduced via money supply process, its significant impact on output from the interest rate channels may yet be exact for positive and negative shocks. Confirming this, is the non-rejection of the null hypothesis of no asymmetry as suggested by the insignificant of the Wald statistics. 


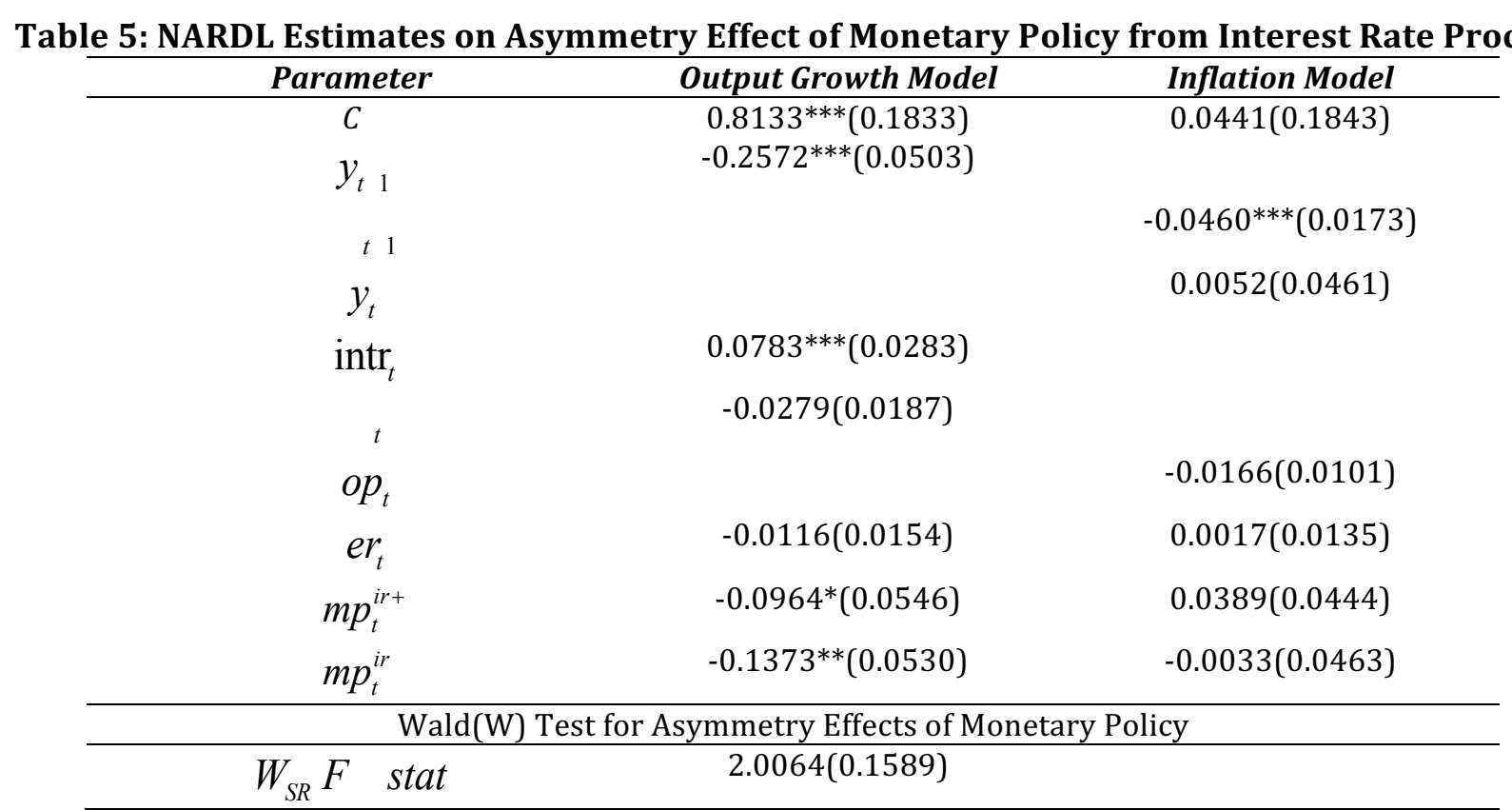

Note: The term $\mathrm{W}$ represents Wald restriction test distributed as distributed as (5) while subscripts SR denotes short run. The values in parenthesis are standard error for the estimates but probability value for the Wald restriction test, while ***, ** and * denote $1 \%, 5 \%$ and $10 \%$ levels of significance.

\section{CONCLUDING REMARK}

Using Nigerian dataset as a representative of developing economies, we hypothesized for the role of uncertainty as potential accelerator of asymmetry effects of monetary policy shocks. This is motivated by the relative higher vulnerability of monetary authorities to exogenous conditions in developing economies compared to the developed ones. While categorizing the uncertainties into internal uncertainty and external uncertainty, we capture the former via political pressure measure as variability of government borrowing, and the latter in the form of variability in the international crude prices. However, our finding tends to identify with variability in government borrowing as the measure with significant potential for explaining the role of uncertainty in the asymmetry effect of monetary policy shocks. Essentially, we explore both money supply and interest rate process using linear and non-linear ARDL to show that political pressure such as variability in government borrowing has the potential to accelerate the asymmetry effect of monetary policy. We also observe the asymmetry effect of monetary policy to be sensitive to the choice of monetary policy indicator. These findings suggest that monetary authorities must consider not only the effectiveness or otherwise of monetary policy instruments to affect the target policy goals, but also the fact that not all the target variables react in a similar way to expansionary and contractionary monetary policy shocks.

\section{References}

Aksoy, Y., De Grauwe, P. and Dewachter, H. (2002). Do asymmetries matter for European monetary policy? European Economic Review, 46, pp. 443-469

Berger, T. and Herz, S. (2013). Global Macro economic Uncertainty. Unpublished Manuscript.

Bernanke, B. and Gertler, M. (1989). Agency costs, net worth, and business fluctuations. American Economic Review, 79 (1), pp. 14-31.

Castro, V. (2011). Can central bank's monetary policy be described by a linear (augmented) Taylor rule or by a non-linear rule? Journal of Financial Stability, 7, pp. 228-246.

Christiano, L.J., Eichenbaum, M. and Evans, C.L. (1997). Monetary policy shocks: what have we learned and to what end? In: Taylor, John B., Woodford, Michael (Eds.), Handbook of Macroeconomics. Elsevier Science, Amsterdam. 
Deekor, L. L. N. (2019). Impact of Monetary Policy Shocks on Macroeconomic Fundamentals: The Role of Asymmetry and Uncertainty in Nigeria. Advances in Social Sciences Research Journal, 6(11) 110-129.

Cover, J.P. (1992). Asymmetric effects of positive and negative money-supply shocks. Quarterly Journal of Economics, 107, pp. 1261-1282.

Cukierman, A. and Muscatelli, V.A. (2008). Nonlinear Taylor rules and asymmetric preferences in central banking: evidence from the United Kingdom and the United States. The BE Journal of Macroeconomics, Contributions 8(1) (article 7).

De Grauwe, P. and Se'ne'gas, M. (2006). Monetary policy design and transmission asymmetry in EMU: Does uncertainty matter? European Journal of Political Economy, 22, pp. 787- 808.

De Grauwe, P. (2000). Monetary policies in the presence of asymmetries. Journal of Common Market Studies, 38, pp. 593-612.

Dornbusch, R., Favero, C. and Giavazzi, F. (1998). Immediate challenges for the European Central Bank. Economic Policy: A European Forum, 26, pp. 15-52.

European Central Bank (2001). Monetary policy-making under uncertainty. Monthly Bulletin, pp. 43-55.

Fang, L., He, L. and Huang, Z. (2018). Asymmetric effects of monetary policy on firm scale in China: A quantile regression approach. Accepted Manuscript. https://doi.org/10.1016/j.ememar.2018.11.013

Georgiadis, G. (2015). Examining asymmetries in the transmission of monetary policy in the euro area: Evidence from a mixed cross-section global VAR model. European Economic Review, 75, pp. 195-215.

Gerlach, S. and Schnabel, G. (2000). The Taylor rule and average interest rates in the EMU-11 area: A note. Mimeo., Bank for International Settlements, Basle.

Gogas, P., Pragidis, L. and Tabak, B.M. (2018). Asymmetric effects of monetary policy in the U.S and Brazil. The Journal of Economic Asymmetries, 18, pp. e00-108

Gros, D. and Hefeker, C. (2002). One size must fit all: national divergences in a monetary union. German Economic Review, 3, pp. 1-16.

Karras, G. (1999). Openness and the effects of monetary policy. Journal of International Money \& Finance, 18(1), pp. 13-26.

Karras, G. (2013). Asymmetric effects of monetary policy with or without Quantitative Easing: Empirical evidence for the US. The Journal of Economic Asymmetries, 10, pp. 1-9.

Kilinc, M. and Tunc, C. (2017). The asymmetric effects of monetary policy on economic activity in Turkey. Structural Change and Economic Dynamics, Accepted Journal, https://doi.org/10.1016/i.strueco.2019.03.006

Lee, D.J. and Yoon, J.H. (2016). The New Keynesian Phillips Curve in multiple quantiles and the asymmetry of monetary policy. Economic Modelling, 55, pp. 102-114

Lo, M.C. and Piger, J. (2005). Is the response of output to monetary policy asymmetric? Evidence from a regimeswitching coefficients model. Journal of Money, Credit, and Banking, 37, pp. 865-887.

Mihov, I. (2001). One monetary policy in EMU: monetary policy implementation and transmission in the European Monetary Union. Economic Policy, 33, 371- 406.

Montes, G.C. (2010). Uncertainties, monetary policy and financial stability: challenges on inflation targeting. Brazilian Journal of political Economy, 30(117), pp. 89-111.

Nolan, C. (2002). Monetary stabilisation policy in a monetary union: some simple analytics. Scottish Journal of Political Economy, 49, pp. 196-215.

Ravn, M.O. and Sola, M. (1996). A reconsideration of the empirical evidence on the asymmetric effect of money supply shocks: positive vs. negative or big vs. small? Unpublished manuscript, University of Aarhus, Denmark.

Ravn, S.H. (2013). Asymmetric monetary policy towards the stock market: A DSGE approach. Journal of Macroeconomics, Article in press, xxx, pp. xxx-xxx.

Salisu, A.A. and Isah, K.O. (2018). Predicting US inflation: Evidence from a new approach. Economic Modelling, DOI: 10.1016/j.econmod.2017.12.008.

Salisu, A.A., Ademuyiwa, A. and Isah, K.O. (2018). Revisiting the forecasting accuracy of Phillips curve: The role of oil price. Energy Economics, 70, pp. 334-356.

Santoro, E., Petrella, I., Pfajfar, D. and Gaffeo, E. (2014). Loss aversion and the asymmetric transmission of monetary policy 
Scot, P.C. (2016). Asymmetric preferences and monetary policy deviations. Journal of Macroeconomics, 50, pp. $325-334$.

Olofin, S.O., Olubusoye, O.E., Mordi, C.NO., Salisu, A.A., Adeleke, A.I, Orekoya, S.O., Olowookere, A.E., and Adebiyi, M.A. (2014). A small macroeconometric model of the Nigerian economy. Economic Modelling, 39, pp. 305-313.

Tan, S., Habibullah, M. and Mohamed, A. (2010). Asymmetric Effects of Monetary Policy in ASEAN-4 Economies. International Research Journal of Finance and Economics, pp. 44, 1450-2887.

Tule, M., Salisu, A.A and Chiemeke, C. (2018). You are what you eat: The role of oil price in Nigeria inflation forecast. Centre for Econometric and Allied Research, University of Ibadan Working Papers Series, CWPS 040

Weise, C. (1999). The asymmetric effects of monetary policy: a nonlinear vector autoregression approach. Journal of Money, Credit, and Banking, 31, pp. 85-108.

Wooheon, R. (1995). Asymmetric effects of money on inflation: Evidence from Korean Data. International Economic Journal, 9(4), pp. 31-43.

Zakri, N. and Malik, W.S. (2013). Are the effects of monetary policy on output asymmetric in Pakistan? Economic Model.ing, 32, pp.1-9.

Zhu, Y. and Chen, H. (2017). The asymmetry of U.S. monetary policy: Evidence from a threshold Taylor rule with time-varying threshold values. Accepted Manuscript, http://dx.doi.org/10.1016/i.physa.2017.01.023 